\title{
Desafios na publicação científica
}

\section{Challenge in scientific publication}

\author{
Gilson Luiz Volpato* \\ Eliane Gonçalves de Freitas**
}

\begin{abstract}
RESUMO: Discutimos os principais problemas que fazem com que um texto científico não seja encontrado, lido ou aceito pelos leitores. Um texto científico é considerado um argumento lógico. Portanto, métodos, resultados e dados da literatura são considerados premissas que suportam as conclusões do trabalho; e na sessão "Introdução", as justificativas corroboram o objetivo do estudo. Esta concepção torna o texto uma estrutura hermeticamente coerente onde somente dados necessários devem ser incluídos (algumas controvérsias são pertinentes). Num segundo passo, mostramos equívocos formais na redação científica, os quais tornam os textos menos atrativos. Assim, damos exemplos de erros e inadequações formais na apresentação de títulos, resumos, resultados (figuras e tabelas) e erros gramaticais em português (também válidos para a gramática inglesa). Posteriormente, enfatizamos a necessidade para redações em língua internacional (inglês) e publicação em periódicos com impacto na comunidade científica internacional. Finalmente, consideramos aspectos para melhora dos periódicos brasileiros na área biológica.
\end{abstract}

DESCRITORES: Divulgação científica; Publicação; Redação; Ciência.

ABSTRACT: We discuss the main problems which make a scientific text difficult to find, to be read or to be accepted by readers. A scientific text is considered a logical argument. Therefore, methods, results and data from literature are premises supporting the conclusions of the work; and in the "Introduction" session, the justification corroborates the objective of the study. This conception makes the text a hermetically coherent structure where only the necessary data should be included (some controversy is still pertinent). In a second step, we show formal mistakes in scientific writing which make texts less attractive. Thus, we give examples of errors or inadequacy of formal aspects of presenting titles, abstracts, results (figures and tables), and grammar mistakes in Portuguese (but also valid for English grammar). After that, we emphasize the need for writing in international language (English) and for publication in periodicals with international impact on the scientific community. Finally, considerations to improve the Brazilian periodicals in the biological area are presented.

DESCRIPTORS: Scientific divulgation; Publication; Redaction; Science.

\section{A ORIGEM DO PROBLEMA}

"Good scientific writing is not a matter of life and death; it is much more serious than that."

(Day $\left.^{3}, 1998\right)$

As publicações científicas de pesquisadores brasileiros têm aumentado vertiginosamente nos últimos anos $\left(\right.$ Souza $\left.^{12}, 2002\right)$. Esse aumento não é apenas numérico absoluto, mas também uma elevação percentual em relação a outros países (Izique $^{6}, 2002$; Souza ${ }^{12}, 2002$ ), como confirmado por dados do ISI (Institute for Scientific Information) e SciELO (Scientific Electronic Library On-line). Mais importante: parece também significar um aumento qualitativo. Isso sem levar em conta as pesquisas de boa qualidade publicadas em veículos não alcançados pelo ISI e SciELO. Embora esse quadro seja animador, acreditamos que há ainda um longo caminho pela frente para uma melhora efetiva na divulgação da pesquisa brasileira.

O principal responsável por esse aumento da produção científica nacional é o sistema de pósgraduação $\left(\right.$ Souza $^{12}$, 2002) que, por meio da CAPES, prioriza o número de artigos publicados para conceituar os programas nacionais. Apesar disso e da qualidade desse sistema, há ainda muito o que melhorar. Algumas de suas normas difundidas em vários programas de pós-graduação (inclusive naqueles considerados de bom nível pela CAPES) representam entraves para um avanço qualitativo mais significativo e têm contribuído para a formação de ultra-especialistas que ainda carecem de uma abordagem mais geral da ciência (vide Volpato ${ }^{13}, 2001$ ). Se isso não for corrigido, muito em breve esses ultra-especialistas estarão

\footnotetext{
*Research Center on Animal Welfare - RECAW; Laboratório de Fisiologia e Comportamento, Departamento de Fisiologia, IBB, UNESP.

** Research Center on Animal Welfare - RECAW; Laboratório de Comportamento Animal, Departamento de Zoologia e Botânica, IBILCE, UNESP.
} 
Volpato GL, Freitas EG de. Desafios na publicação científica. Pesqui Odontol Bras 2003;17(Supl 1):49-56.

definindo normas macros da ciência no País, o que pode levar a significativos lapsos qualitativos na ciência nacional.

Apesar da divulgação informal da ciência (via congressos, palestras, visitas etc.) permitir uma rápida veiculação da informação recente (Población, Duarte ${ }^{10}, 1989$ ), é apenas a divulgação formal (publicação) que dá credibilidade suficiente para que a informação seja aceita como suporte para outros trabalhos. Mesmo assim, não há consenso internacional sobre como avaliar a produção científica (Souza $\left.{ }^{12}, 2002\right)$, o que torna essa atividade árdua, controversa e problemática; mas, ainda assim, necessária. Embora no Brasil muitos pesquisadores ainda lutem para aumentar suas modestas taxas de publicações anuais, no quadro internacional a divulgação científica não tem se resumido ao número de artigos publicados. A corrida, já há vários anos, é pelo número de citações do que é publicado.

Enquanto alguns autores têm seus artigos no completo anonimato após a publicação, mesmo em periódicos de reconhecido nome internacional, outros conseguem taxas de centenas ou até milhares de citações. Com as facilidades na comunicação global, essa pressão chegou ao Brasil há alguns anos e dominará em breve nos trâmites da ciência nacional.

Citando um exemplo, em 1996, durante visita ao Institute of Freshwater Ecology, Ambleside, na Inglaterra, percebemos que um dos critérios adotados pelo chefe da equipe para a escolha de artigos a serem citados era o número de citação que o artigo já havia recebido. Ou seja, dentre os artigos possiveis para a citação, priorizava os já consagrados pela literatura internacional. Por estranho que possa parecer, isso tem razões lógicas e científicas. Num texto científico, a citação bibliográfica valida a informação perante a comunidade científica. Portanto, nada melhor que escolher aquelas já aceitas pela comunidade como sendo boa base para a informação. Evidentemente, não é só isso que ocorre. Artigos dos chamados países desenvolvidos acabam sendo priorizados e, nesses casos, pode se tratar exclusivamente de preconceito.

Segundo Day $^{3}$ (1998), e possivelmente muitos outros pesquisadores, um experimento científico estará concluído apenas se publicado. No entanto, entendemos que isso é apenas parte do problema. No quadro que esboçamos, a publicação se torna o meio, mas não o fim. Ela é o passo óbvio para que se tenha a possibilidade de que o conhecimento ge- rado adentre pela comunidade científica de interesse (geralmente em nivel internacional). Segundo Volpato ${ }^{13}$ (2001), o conhecimento científico é aquele que é gerado pelo método científico (seja como for concebido) e aceito por parcela significativa da comunidade científica. Esse autor argumenta que as respostas científicas às questões são dadas pelos cientistas com base nos textos que conhecem e aceitam. As publicações que ficam esquecidas em estantes de bibliotecas não adentram a ciência, e podem ou não adentrá-la no futuro, mas isso será sempre incerto. Portanto, conclui Volpato $^{13,14}(2001,2002)$, não basta publicar, é preciso que o texto seja encontrado, lido e aceito. Esse é o grande desafio da publicação científica nos dias de hoje e muda radicalmente vários conceitos na publicação científica.

Day $^{3}$ (1998) compara a publicação científica ao seguinte fato. Quando uma árvore cai no meio de uma floresta, não podemos dizer que sua queda produziu um som, a menos que tenha alguém para ouvi-lo. Caso contrário, ocorrem apenas ondas de pressão. Para que haja som é necessário um receptor para captar esse sinal. Se um trabalho científico não for lido, entendido e aceito, será apenas uma árvore caindo silenciosamente no meio da floresta.

No seguimento deste texto abordaremos questões lógicas e estruturais do trabalho científico, procurando fornecer caminhos que facilitem a divulgação da idéia. É nesse ambiente que questões éticas não devem ser esquecidas, sendo a autoria uma delas. Dentre as várias publicações sobre esse tema, uma merece distinção. É a proposta de Maddox $^{8}$ (1994), que sintetiza dizendo que o autor (seja ou não o primeiro autor) deve ter participado da história do trabalho e ser apto a defendê-lo, em sua estrutura básica, perante a comunidade científica. É o respeito a isso e à qualidade dos dados obtidos e análises encetadas que garante a validade do que se segue neste texto.

$\mathrm{Na}$ divulgação científica, três aspectos estruturais são prioritários: a lógica e consistência interna do estudo; a forma adequada e convincente de apresentação; e a adequação do veículo e idioma de publicação. São esses os aspectos discutidos a seguir.

\section{LÓGICA E CONSISTÊNCIA INTERNA DO ESTUDO}

Volpato $^{14}$ (2002) compara o artigo científico (ou tese e dissertação) a um argumento lógico. Um ar- 
Volpato GL, Freitas EG de. Desafios na publicação científica. Pesqui Odontol Bras 2003;17(Supl 1):49-56.

gumento é constituído de premissas e conclusão. No artigo científico, a Introdução é um argumento, no qual premissas levam à conclusão de qual seja o objetivo do trabalho. O restante do texto é um segundo argumento que demonstra a validade das conclusões. Assim, Material e Métodos, Resultados e Discussão fornecem as premissas com o objetivo inequívoco de corroborar as conclusões. Nessa visão, o texto científico deve ser sintético, apresentando apenas as premissas necessárias e suficientes para sustentação do objetivo do trabalho e de suas conclusões. Qualquer informação que não atinja essa finalidade deve ser excluída. No caso de dados que contrariam a conclusão do autor, devem ser incluídos formando parte do argumento (nesse caso, a conclusão tem exceções ou é modificada). É essa estrutura fechada e bem articulada que dá ao texto científico sua qualidade. É a percepção clara dessa estrutura que permite ao pesquisador redigir um bom texto. Segundo informações pessoais de vários editores internacionais, a principal dificuldade dos manuscritos de brasileiros para publicação em periódicos de boa qualidade internacional não é o inglês, mas sim a estruturação equivocada do artigo e falta de estilo científico (enquete feita pelo Dr. Wagner C. Valenti, Departamento de Biologia Aplicada, FCAV, Jaboticabal, UNESP; informação pessoal).

Uma técnica de redação muito usada, mas nem sempre compreendida pelos autores, é a Redação de Trás para a Frente (aqui referida como RTF). Nessa técnica o argumento é redigido partindo-se da conclusão e retrocedendo-se até o início. Ela foi sintetizada por Magnusson ${ }^{9}$ (1996) e é detalhada em Volpato ${ }^{13}$ (2001). O uso dessa técnica pressupõe que o argumento científico desenvolvido já tenha sido devidamente criticado e depurado pelo pesquisador. Ou seja, o autor já está convencido da adequação do argumento (validade do objetivo e adequação de métodos, resultados, comparações e conclusões). Só então deve iniciar a redação do texto (nada de redigir Material e Métodos enquanto termina de coletar dados!). Segundo a RTF, os passos são os seguintes:

1) Redija as conclusões do trabalho (geralmente são poucas). Lembre-se de que são escritas no presente, pois não se referem à amostra examinada, mas à população da qual se quer referir.

2) Escolha agora os resultados que obteve e que são necessários para sustentarem as conclusões.
3) Escolha a melhor forma de apresentar esses resultados (figuras, tabelas ou texto), procurando evidenciar os principais elementos que fundamentam as conclusões.

4) Redija o item Resultados.

5) Redija o item Material e Métodos, indicando aí apenas a metodologia necessária para os resultados apresentados, ou mesmo aquela que não produziu dados úteis, mas que pode ter afetado a condição experimental. Se não for um desses dois casos, simplesmente exclua (lembre-se, o artigo não é um relatório: é um argumento). Primeiro caracterize sua população de estudo, ou amostra; em seguida, informe sua estratégia de pesquisa (delineamento); depois especifique detalhes da metodologia (como mediu as variáveis, quais os equipamentos, técnicas específicas usadas etc.); finalmente, informe como analisou os dados (este último item pode ser suprimido, se foi incluído na apresentação dos resultados).

6) Redija a Discussão, seguindo a forma argumentativa mais adequada. Os dados da literatura são usados para validar as técnicas, os resultados e as conclusões obtidas, bem como fornecer informações que possibilitam ampliar as conclusões. Não há regras rígidas. É um texto argumentativo. Cite as referências necessárias, e de boa qualidade, independentemente de estarem ou não citadas em outras partes do texto.

Com isso, você concluiu o argumento principal do texto, que é o que dá suporte às conclusões (lembre-se, a essência de um artigo científico não são seus dados, mas sim suas conclusões!). Agora, redija a Introdução do trabalho. Seja sintético e incisivo ao mostrar o problema investigado e as justificativas que suportam o objetivo proposto. Definições de termos e importância do estudo podem ser incluídos, se estritamente necessários.

Uma vez concluídos esses dois blocos fundamentais do texto científico, [(Introdução) + (Material e Métodos, Resultados e Discussão)], redija Resumo, Titulo, Palavras-chave, Agradecimentos, Apoio Financeiro e Endereços.

Como a estrutura lógica dá consistência ao texto, uma importante etapa já foi então vencida. Mas ela é apenas o começo!

\section{FORMA ADEQUADA E CONVINCENTE DE APRESENTAÇÃO}

A estruturação lógica adequada mostrada acima é, sem dúvida, importante na construção de 
Volpato GL, Freitas EG de. Desafios na publicação científica. Pesqui Odontol Bras 2003;17(Supl 1):49-56.

um texto científico elegante. Mas há equívocos formais que podem comprometer essa elegância (raramente a consistência lógica). São equívocos que raramente encontramos em revistas de boa qualidade internacional. A seguir, resumimos os principais deles e que influem diretamente no processo de escolha do artigo pelo leitor. Lembre-se que não basta publicar, é necessário ser lido e aceito.

Uma forma simples de avaliar quais são as chances de seu texto ser lido é compará-lo aos textos que gostamos de ler, que são simples, claros, bem apresentados, bonitos. Por exemplo, não gostamos de títulos imensos que, de tão longos, nem conseguimos memorizá-los. Nem de textos prolixos, tabelas imensas, gráficos complicados. A regra é mais de bom senso do que normativa. Atualmente, a velocidade com que as informações nos chegam é avassaladora. O problema não é mais conseguir a informação, mas sim triá-la. É nesse contexto que nossos artigos vão ser escolhidos, ou não.

O primeiro contato do leitor com o artigo é pelo Título, ainda na fase de revisão da literatura nos indexadores. Se seu trabalho for rejeitado aí, já não será lido. A segunda fase é a leitura do Resumo. Passadas essas duas barreiras, o leitor pode selecionar seu texto. Nessa terceira fase ele poderá ler seu artigo, mas apenas se sentir-se atraído com a folheada que dará na separata. E nessa folheada observará principalmente Figuras e Tabelas. Se elas dão informações relevantes e interessantes, certamente se empenhará na leitura do texto. Caso contrário, poderá ser mais um daqueles artigos que nunca serão lidos, só arquivados.

A seguir são apresentadas características norteadoras para elaboração desses três tópicos do trabalho científico, cujos principios foram extraídos de Volpato ${ }^{13,14}$ (2001; 2002).

\section{Título}

O título deve expressar a essência do trabalho: conclusão ou objetivo. Deve ser sintético, pois atualmente o leitor se depara com uma avalanche de títulos de artigos, podendo rejeitar alguns simplesmente por não serem lidos na íntegra. $O$ título pode ser uma frase completa, com sujeito, verbo e complemento, ou descrever apenas o conjunto de variáveis investigadas. Não há uma regra geral, pois a criatividade deve imperar. Só não se esqueça de que ele não pode ser enganoso, referindo-se a aspectos marginais do estudo. $\mathrm{O}$ uso de termos muito específicos também reduz o número de leitores que o compreendem.

\section{Resumo}

Como o nome diz, contém uma síntese do trabalho. Para isso, é fundamental que o autor tenha uma noção muito clara da estrutura lógica e argumentativa de seu trabalho. Fundamentalmente, um resumo pode conter: justificativas, objetivos, estratégia experimental, principais resultados e conclusões. Se formos excluir alguns desses tópicos, a última informação a ser retirada é a conclusão, pois é a essência do argumento. A primeira delas são as justificativas, podendo-se iniciar o resumo diretamente com o objetivo da pesquisa. Mas se ainda for necessário excluir mais algum tópico, geralmente é mais apropriado excluir os resultados e não o delineamento. Fica dificil entender os resultados se a estratégia da pesquisa é omitida. Afinal, o resumo é considerado uma carta de intenções $\left(V_{0 l p a t o}{ }^{14}, 2002\right)$. Nesse sentido, ele informa onde o autor pretendeu chegar, e onde acha que chegou, mas é necessário ler o artigo na integra. Mesmo assim, como em qualquer outro tópico de um texto científico, lembramos que redação é arte e regras rígidas não ajudam muito. Muitas vezes uma associação entre título e objetivo já esclarecem a estratégia da pesquisa, de forma que os resultados podem ser incluídos e o delineamento excluído sem prejuízos.

\section{Figuras e Tabelas}

Devem ser claras e sintéticas. Evite incluir várias informações num mesmo gráfico, embora uma figura possa conter alguns gráficos. Cada linha ou símbolo inserido num gráfico ajudará ou atrapalhará o leitor. Pense criticamente nisso. Alguns equívocos comuns são listados abaixo.

1) Uso de erro padrão da média (EPM): em dados com alta variabilidade, é comum que alguns pesquisadores sintam-se compelidos a usar o EPM ao invés do tradicional desvio-padrão. De fato, o EPM é calculado como o desvio-padrão dividido pela raiz quadrada do número de réplicas amostrado. Assim, o parâmetro fica bem reduzido. Mas isso é fonte de equívocos (vide também Cleveland, McGilli2, 1985). Primeiramente, o que se pretende mostrar? É a variabilidade dos dados ao redor da média? Então, deve-se usar o desvio-padrão. Mais que isso, se o número de réplicas não é o mesmo entre as amostras comparadas, então o desvio-padrão é 
necessário para não enganar ou prejudicar o entendimento do leitor. O EPM é uma medida estatística e não pode ser considerado um costume dentro de uma área de pesquisa. Erro gritante ocorre também quando valores de tendência central (por ex., média) são apresentados sem as respectivas variabilidades. Dados médios sem os respectivos desvios-padrões não têm significado biológico e comprometem a aceitação do trabalho pela comunidade científica.

2) Escalas com muitas divisões: lembre-se que o gráfico mostra valores por meio de escalas. Isso basta. Não precisa encher a escala com números. Apenas alguns são suficientes para nortear o leitor e tornar a apresentação clara. O valor específico da média ou da freqüência apresentada raramente é requerido num trabalho científico. A ciência busca generalizações a partir de dados (Chalmers ${ }^{1}$, 1993) e a repetição de uma pesquisa não implica que encontremos os mesmos dados, mas sim as mesmas generalizações (conclusões). Outro erro de representação gráfica que expressa a mesma ignorância em termos de ciência é a apresentação de gráficos com valores expressos em barras e, acima delas, os valores médios expressos numericamente.

3) Gráficos em pizza: forma geralmente não recomendada. Ela não enfatiza as diferenças entre os valores (a espécie humana percebe melhor as diferenças visuais de comprimento do que as de área). Além disso, no caso de medidas de média ou mediana, não permite a inclusão de indicadores da variabilidade (desvio-padrão, quartil, amplitude etc.).

4) Uso equivocado da estatística: o pesquisador mostra seus dados, com diferença de cerca de $20 \%$ entre as médias, mas cujos desvios impedem aceitá-las como estatisticamente diferentes entre si. Ou seja, não ocorreu diferença estatisticamente significativa, mas o autor pode ficar motivado a dizer que a diferença é real e deve ser considerada. Por exemplo, faz isso usando o equivocado argumento de que, em termos de produção, a diferença percentual é importante, mesmo não tendo sido detectada ao nivel estatístico. Grave erro! Se a diferença é estatisticamente não significativa, implica que, ao repetir a situação, os dados possam ter suas médias até invertidas (se $A$ era maior que $B$, na repetição $B$ pode ser maior que $A$ ). Isso pode gerar recomendações de condutas completamente equivocadas, levando a tratamentos ineficazes ou até prejudiciais. Se o recurso estatístico foi considerado apropriado, então o assuma até o final. Use a estatística, mas use-a corretamente.

5) Símbolos vazios: para resumir conceitos, é comum os autores usarem abreviaturas (por ex., UG, SNC, A, III etc.). Mas muitas vezes usam símbolos não necessários, ou mesmo simbologia inapropriada. O símbolo deve ser simples e de fácil memorização pelo leitor. Portanto, deve haver alguma ligação lógica entre ele e seu significado. Por exemplo, abreviar grupos experimentais por G-I, G-II, G-III e G-IV é completamente falho nesse aspecto, pois fica dificil lembrar o que representam. Mais elucidativo seria ISO para representar situação de isolamento e G5, G10 e G15 para os casos de agrupamento nas diferentes densidades $(5,10$ e 15 animais por espaço). O mesmo acontece na referência a gráficos. Uma figura pode conter, por ex., dois gráficos (A e B). Na legenda da figura o leitor encontrará que $\mathrm{A}=$ machos e $\mathrm{B}=$ fêmeas. Experimente substituir no gráfico as letras A e $B$ pelo que representam (machos e fêmeas) e verá que a apreensão da informação é muito mais rápida e fácil.

\section{Redação}

De nada vale um texto bem estruturado em seu conteúdo e formas gráficas, se a redação das frases é precária. A gramática de nosso idioma é complexa e os textos científicos em revistas nacionais geralmente apresentam erros. Mas há alguns que são mais gritantes e comuns e devem ser necessariamente eliminados. Listamos abaixo equívocos de redação que são muito freqüentes em artigos publicados em periódicos nacionais. Alguns deles extrapolam nossa gramática e são também válidos na gramática inglesa.

1) Vírgula: a colocação de vírgula entre sujeito e verbo é um erro comum (da pré-escola à universidade). A vírgula não pode interromper uma ação. Esqueça o conselho de que a vírgula aparece quando você pára para respirar. A regra é lógica e não biológica. Sujeito, verbo e complemento não podem ser separados por vírgula, mas se houver algum elemento entre eles, então esse elemento será isolado por pontuação (parênteses, virgula etc.). Na frase "Os principais carboidratos provenientes de alimento de origem animal, são de dificil avaliação", a colocação de virgula entre animal e são representa um erro 
Volpato GL, Freitas EG de. Desafios na publicação científica. Pesqui Odontol Bras 2003;17(Supl 1):49-56.

freqüente (comum nos casos em que o sujeito envolve vários termos). Quando a vírgula aparece, será sempre duas e não uma, e separará um aposto explicativo. Por exemplo, "A mandioca, alimento bem apreciado no Brasil, é uma raiz”. Caso comum é quando há citação de autor. Neste caso há vírgula: "Segundo Silva (1997), o sujeito causou a ação". Aqui não há vírgula: "Silva (1997) observou que o sujeito causou a ação". Lembre-se que vírgula pode separar duas idéias numa frase, como em "Hoje está chovendo, mas espero que amanhã apareça o sol".

2) Concordância verbal: o equivoco mais comum é quando o núcleo central do verbo está no singular e outros elementos no plural, com o autor usando o verbo no plural (ou vice-versa). Por exemplo: "O significado dos testes laboratoriais realizados com todos os ratos são impressionantes". O correto é usar o verbo é ao invés de são, pois deve concordar com significado. Quem é impressionante não são os ratos e nem os testes, mas sim o significado dos testes. Outro erro é a ortografia no caso do verbo ter (ou derivados): "Eles têm azar e você tem sorte" (no plural, esse verbo possui acento circunflexo).

3) Conjunção: uma rápida consulta no dicionário sobre a palavra conjunção revela quase trinta tipos de conjunção. São elementos que ligam idéias (na frase e entre frases ou parágrafos). Elas informam ao leitor qual relação que a informação que está por vir tem com a informação passada. Em "Os preços baixaram e meu salário aumentou; portanto, espero melhorar meu orçmento", a conjunção portanto mostra que o que vem após esse termo é uma conseqüência lógica do que foi dito anteriormente... e de fato é. Se a conjunção é "Por outro lado", espera-se que a idéia a vir seja contrária à anterior. É a colocação da conjunção correta que dá o colorido ao texto, tornando-o mais uma seqüência argumentativa de idéias, que um aglomerado de informações.

4) Prolixidade: é o uso de mais palavras que o necessário. Se podemos expressar algo em 10 palavras, no estilo científico não devemos usar mais que isso. Não adianta o autor alegar que se trata de seu estilo. O estilo científico exige brevidade. Para a publicação científica isso é vital. Artigos prolixos consomem desnecessariamente muitas páginas, reduzindo o número de artigos a serem publicados no mesmo volume ou fascículo. Como conseqüência, menor número de autores são publicados, reduzindo o número de leitores potenciais e também a chance de citação pela comunidade científica, refletindo no fator de impacto da revista. Um caso comum de prolixidade é quando usamos duas palavras para expressar uma ação: "A temperatura provocou aumento do metabolismo", quando deveríamos simplesmente escrever "A temperatura elevou o metabolismo".

5) Forma direta de expressão: prefira colocar a causa antes do efeito. É lógico e causa menos confusão. Assim, prefira dizer " $A$ adrenalina elevou a atividade cardiaca" do que dizer "A freqüência cardiaca foi elevada pela adrenalina". Além disso, é mais econômico.

\section{PERIÓDICO E IDIOMA DE PUBLICAÇÃO 0 idioma}

O alcance de um texto científico é definido pelas conclusões geradas. Aquelas de interesse para a comunidade internacional devem ser publicadas em veículos que atinjam essa comunidade. Mas é bom lembrarmos que uma pesquisa não tem alcance nacional simplesmente porque estuda uma comunidade brasileira ou uma espécie típica deste País. O mais comum na ciência é que as amostras estudadas sejam modelos que geram conclusões válidas para populações mais amplas. Tanto é assim que esses trabalhos geralmente citam estudos feitos em vários países, com diferentes modelos de investigação. É esse conceito, tão inerente à atividade científica, que muitas vezes é esquecido em pesquisas de interesse internacional, quando ficam restritas ao alcance do idioma português. Por exemplo, os estudos da educadora Emília Ferreiro, por mais que tenham sido baseados em crianças de um mesmo país, desdobraram-se numa abordagem de alfabetização (o construtivismo) não restrito a um único país. O mesmo se pode dizer do método de alfabetização desenvolvido por Paulo Freire. Nas Ciências Biológicas não é diferente. Problemas e técnicas em Odontologia podem emergir de casos restritos, mas desdobrarem-se em condutas gerais de interesse a qualquer país. $O$ que vemos é que, nessa perspectiva, raramente temos estudos de interesse regional. O que falta a muitos autores é a percepção disso e a disposição para generalizar suas conclusões (para melhor embasamento teórico e filosófico das generalizações na ciência, vide, por exemplo, o histórico debate entre Sir Karl Popper e Thomas S. Kuhn, transcrito em Lakatos, Musgrave ${ }^{7}$, 1979). 
Assim, o comum nas publicações científicas é atingir a comunidade nacional e internacional, o que requer um idioma compativel. Segundo Garfield ${ }^{4}$ (1983), o idioma inglês é a língua franca da ciência. Já em 1981, ele constatou que $88 \%$ dos 605.000 artigos indexados eram escritos em inglês. Sem dúvida, nas áreas Biológicas e Exatas, o idioma é o inglês! No caso de vários temas de Humanidades, ainda se admite uma conversação mais restrita, de alcance na América Latina para os brasileiros. Um caso raro é a Revista de Literatura Comparada, cujo idioma oficial é o português, mesmo para os autores estrangeiros que nela publicam. Mesmo assim, em 1982 Roche, Freitas ${ }^{11}$ afirmaram que a ciência naquela época já não falava espanhol e nem tampouco português.

\section{0 periódico}

Ele deve ter penetração e respeitabilidade na comunidade científica (geralmente a internacional). É um sério equívoco enviar textos a periódicos de baixo escalão, com o que se consegue apenas uma linha a mais no currículo do pesquisador, mas nada em termos de ciência (Volpato ${ }^{13}, 2001$ ). Os periódicos de bom nível têm amplo alcance, levando suas idéias a pessoas de várias partes do mundo. Além disso, o crivo crítico aos manuscritos é muito maior, reduzindo muito os erros formais e lógico-estruturais. Em análises em disciplinas de pós-graduação, temos constatado numericamente essas diferenças que refletem toda uma história do manuscrito à publicação. Além disso, refletem também acertos conceituais do corpo editorial dessas revistas de boa qualidade.

Assim, é um sério equívoco iniciar a vida científica enviando manuscritos a revistas de baixa qualidade, com a esperança de melhorar a qualidade de suas publicações no futuro $\left(\right.$ Volpato $^{13}, 2001$ ). Quando o autor publica, imagina que seu texto está correto. O problema é que editores e assessores desses periódicos podem ter equívocos conceituais que são passados ao autor. Com isso, no periódico de baixa qualidade o iniciante aprende coisas que terá que esquecer ao pretender publicar nos veículos de repercussão internacional.

\section{A procura de solução}

Ao enviarmos nossos manuscritos para as revistas de bom nivel internacional, o que acontecerá com aquelas que ainda não atingiram esse patamar? Temos no Brasil cerca de 15 periódicos de excelente nível, catalogados no ISI. Nos arriscamos a pontuar o Brazilian Journal of Medical and Biological Research e Memórias do Instituto Oswaldo Cruz, como as duas revistas mais bem conceituadas do Brasil na área biológica. Como melhorá-las? Como melhorar as outras revistas?

A estratégia é, sem dúvida, o envio de artigos de excelente qualidade e interesse internacional para essas revistas. Mesmo assim, lidamos sempre com o preconceito dos países desenvolvidos, como bem apontado por Gibbs ${ }^{5}$ (1995). Nosso canal de comunicação tem que ser mediado por revistas de excelente qualidade, mas não podemos deixar de incluir nesse rol o que temos de bom em nosso País. Isso não significa dizer que qualquer revista de respeitabilidade nacional esteja no mesmo patamar. Cabe aos editores dessas revistas estabelecerem políticas agressivas e urgentes para a conquista do mercado internacional (começando por adotar o idioma inglês). O trabalho é árduo, mas as duas revistas que citamos acima mostram que é viável. E só assim estaremos ajudando a ciência nacional, mais do que o nosso próprio currículo.

Se o aumento da produção científica nacional no panorama internacional é algo que nos alegra, deve agora ser usado para fortalecer ainda mais nossas revistas no cenário internacional. Com isso estaremos sendo nacionalistas e mostrando que no Brasil também se produz ciência de qualidade. Mas para isso é preciso mais que número de publicações. Nossa pós-graduação tem que ser direcionada para garantir ensino desta arte dificil e fundamental, que é a redação científica. Enquanto ela for suposta como inerente e natural em qualquer pesquisador, nunca teremos o salto qualitativo necessário. É uma habilidade a ser aprendida. Esse é apenas um dos aspectos que a pós-graduação nacional ainda tem que zelar, já que a maioria dos equívocos apontados neste artigo é ainda freqüente nas teses e dissertações arquivadas mesmo nas bibliotecas de nossas melhores universidades.

\section{AGRADECIMENTOS}

Os autores agradecem a Fernanda Moreno Sanchez por críticas a aspectos estéticos do texto. 


\section{REFERÊNCIAS}

1. Chalmers AF. O que é ciência afinal? São Paulo: Brasiliense; 1993.

2. Cleveland WS, McGill R. Graphical perception and graphical methods for analyzing scientific data. Science 1985; 229:828-33.

3. Day RA. How to write \& publish a scientific paper. $5^{\mathrm{a}}$ ed. Phoenix: The Oryx Press; 1998.

4. Garfield FE. Mapping science in the third world. Science and public police 1983; June: 112-27.

5. Gibbs WW. Lost science in the third world. Scientific American 1995; 273(2):76-83.

6. Izique C. Produção crescente. Pesquisa FAPESP 2002; 81:18-22.

7. Lakatos I, Musgrave A. A crítica e o desenvolvimento do conhecimento. São Paulo: EDUSP; 1979.

8. Maddox J. Making publication more respectable. Nature 1994; 369:353.

9. Magnusson WE. How to write backwards. Bull Ecol Soc Am 1996; 77(2):88.

10. Población DA, Duarte JG. Comunicação da informação científica entre pesquisadores. Intercom: Revista Brasileira de Comunicação 1989;12(61):47-61.

11. Roche M, Freitas Y. Producción y flujo de información científica en un país periférico americano. Interciencia 1982; 7:287.

12. Souza PR. O crescimento da produção científica. Folha de São Paulo 2002; Nov 06. p. A3.

13. Volpato GL. Ciência: da filosofia à publicação. $3^{\mathrm{a}}$ ed. Jaboticabal: FUNEP; 2001.

14. Volpato GL. Publicação científica. Botucatu: Santana; 2002.

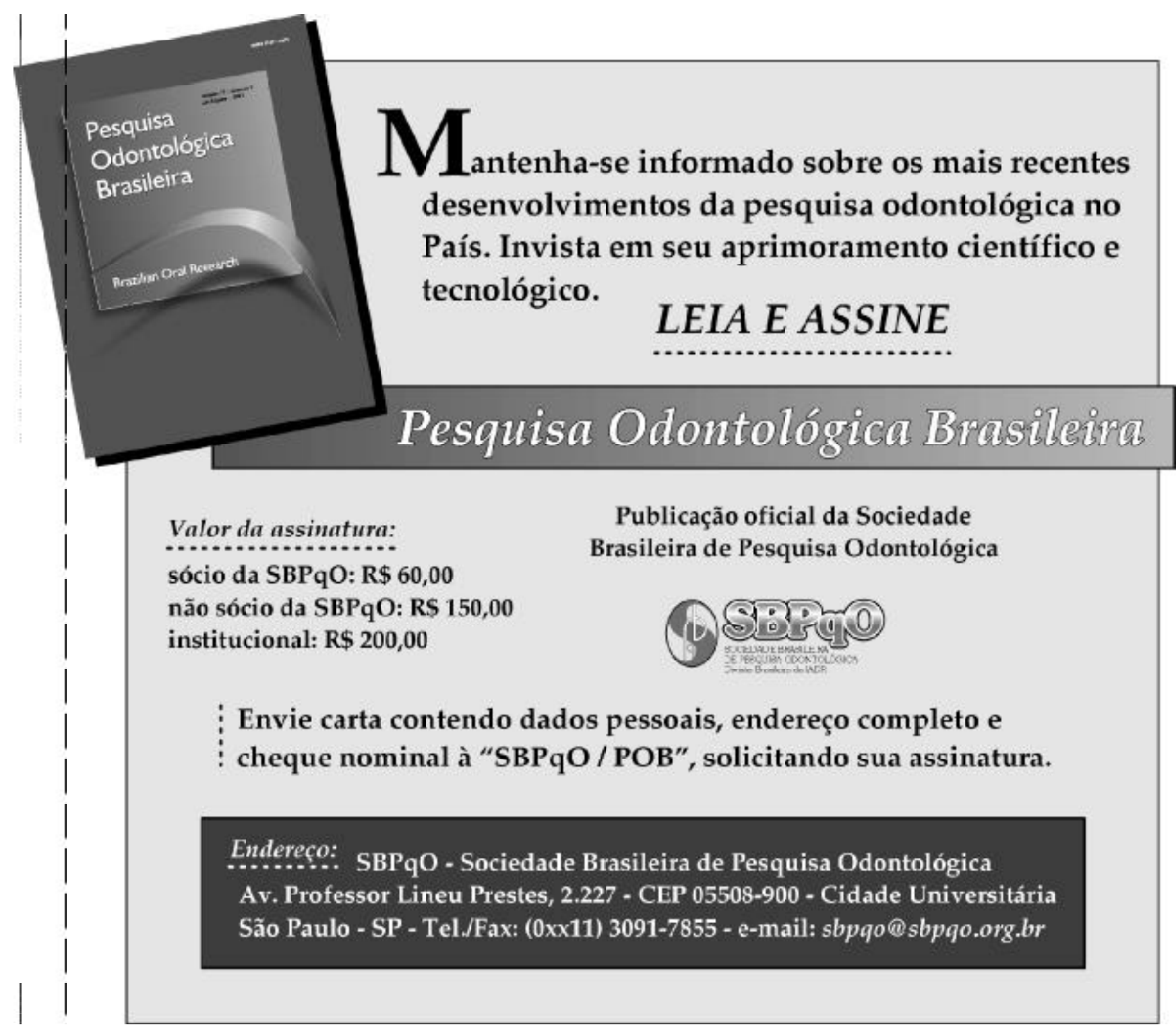

